\title{
Os Invisíveis da UEMG e Outras Invisibilidades na Educação em Tempos de Pandemia
}

Mário Geraldo Rocha da Fonseca

resumo:

O artigo aproxima a realidade de alunos e professores da Universidade do Estado de Minas Gerais (UEMG), de modo particular dos cursos de Design, em situação de vulnerabilidade, àquela que apareceu depois do lançamento do auxílio emergencial do Governo Federal e que foi chamada de invisíveis. Na verdade, o que apareceu foi mais uma das facetas da desigualdade social crônica do Brasil, já diagnosticada pelos estudos do sociólogo Florestan Fernandes entre as décadas de 1940 e 1970. Autocracia burguesa foi um dos conceitos que ele forjou para tentar observar como o sistema econômico produz as mais diversas formas de manter a disparidade entre uma minoria que detém mais da metade da renda per capita do país e uma imensa parcela da população totalmente desassistida e que só tende a crescer em uma situação de pós-pandemia.

palavras-chave:

invisíveis; desigualdade social; autocracia burguesa 


\section{Invisibilidades}

\subsection{Invisíveis na Sociedade}

A dialética perversa que se fez ver por causa da pandemia de covid-19 no Brasil teve e tem efeitos devastadores na educação. Isso, claro, atingiu diretamente as universidades, de modo particular as públicas. Neste artigo, vamos lançar um foco sobre o efeito que foi possível observar na Universidade do Estado de Minas Gerais (UEMG) para tentar caminhos que possam nos ajudar a recolocar um tema que, na verdade, nunca saiu de pauta, embora apresente facetas sempre mais desafiadoras: a desigualdade social, doença crônica do Brasil, bem mais perigosa do que aquela causada pelo novo corona vírus, que já é terrível.

No âmbito da educação, o primeiro semestre de 2020 foi praticamente "perdido" devido às medidas para conter o contágio da covid, que, ao se instalar definitivamente no Brasil, em março deste ano, alastrou-se com velocidade impressionante, chegando, no início de setembro, à absurda marca de quase 130 mil mortos e mais de 4 milhões de contaminados. O que seria, então, este "perdido" no qual as escolas se encontraram, sem saber que medida tomar, tendo em vista que a solução mais indicada para lidar com o problema, a aula remota, esbarrava em uma série de dúvidas a respeito não apenas da sua eficácia didática, mas também quanto à sua viabilidade técnica? Em setembro de 2020, a maioria das escolas, no entanto, optou por se arriscar no ensino online, já que se viram pressionadas por governos e grupos sociais a, de qualquer maneira, começar o ano letivo.

O semestre, porém, segue crivado de dúvidas, sobre as quais queremos fazer eco para pensar na situação de muitos alunos, professores, funcionários, membros da comunidade escolar de modo geral que também podem ser chamados de invisíveis, para aplicar o termo que se tornou conhecido para qualificar uma enorme parcela de brasileiros cuja existência era praticamente ignorada pelas políticas públicas até que a pandemia, que mexeu com as entranhas da desigualdade enraizada no seio da população brasileira, acabou por nos lembrar, mais uma vez: fomos e continuamos a ser um dos países do mundo em que a disparidade entre pessoas com muita renda, a minoria, convive com a maioria que não apenas possui o mínimo, mas também até este mínimo veio a faltar devido ao isolamento social que tirou a renda, mesmo mínima, de muitas pessoas.

Exatamente para ajudar os que haviam perdido o pouco que tinham, o Congresso Nacional aprovou, em abril, o chamado auxílio emergencial que o Governo Federal, a princípio reticente em relação à medida, acabou por acatar, estendendo, inclusive, o seu prazo de vigência, inicialmente, dois meses (abril, maio), até dezembro. ${ }^{1}$ Sem isso, a situação poderia piorar ainda mais, conforme avaliaram os técnicos do Governo, não deixando de incluir na avaliação positiva o efeito político que a medida passou a ter na popularidade do mandatário do Executivo, até então em franca decadência.

O Governo Federal não contava, porém, que a população dos que precisariam de ajuda emergencial era bem maior do que indicavam os cadastros de renda mínima do próprio Governo. E mais: manifestaram-se também aqueles que, mesmo não estando nos registros oficiais, tinham direito ao auxílio. Nos cálculos governamentais, isso já havia sido previsto, mas nunca apontaria uma cifra em torno de 50 milhões! Atônitos, os burocratas federais passaram a se perguntar: quem poderiam ser e por que estariam assim tão invisíveis, já que os dados que os indicariam eram totalmente desconhecidos dos gestores públicos? Fora inclusive do Bolsa Família, programa de maior capilaridade social do Brasil, como essa população iria comprovar que teria direito ao auxílio, uma vez que não tinha nem mesmo como comprovar, para os técnicos de Brasília, a própria existência?

De fato, quando entidades de assistência social tentaram ajudar essa população a fazer o pedido do auxílio, depararam com a realidade de pessoas que, além de não possuírem os documentos básicos, como a Carteira de Identidade, o FGTS ou mesmo a Certidão de Nascimento, não tinham renda nem as condições básicas de moradia e assistência à saúde, tampouco qualquer vínculo com a educação formal. Não restou a essas entidades alternativa alguma, a não ser prestar um serviço social dos mais básicos, já que se tratava de pessoas desassistidas no sentido mais amplo do termo.

O que, no entanto, era invisivel para o Governo tratava-se de uma velha realidade conhecida de várias entidades que trabalham na defesa dos direitos humanos. Não foi, portanto, um espanto ver que,

\footnotetext{
${ }^{1}$ De setembro a dezembro, o valor do auxílio foi reduzido pela metade, ficando em $\mathrm{R} \$ 300,00$.
} 
no momento em que as cidades se tornaram vazias devido ao isolamento social, uma parcela considerável da população que não tinha para onde ir ficou no lugar de sempre: nas ruas e praças, único lugar, na verdade, que encontrou para morar. Foi assim que os moradores de rua puderam, então, ser vistos nos lugares onde, no entanto, sempre estiveram. Imaginou-se, por exemplo, que a Praça da Estação, em Belo Horizonte, por ser um lugar de passagem para muitos trabalhadores que moram na periferia, estaria vazia em abril, mês em que o comércio do centro da cidade ficou totalmente fechado. Ledo engano! As aglomerações no local foram constantes, diríamos permanentes, durante todo o período de maior adesão à quarentena. Aglomeração não apenas de pessoas, mas também de barracas, muitas improvisadas com papelão, madeira carcomida e outros materiais encontrados em entulhos que pudessem dar algum tipo de proteção no momento de maior disseminação de um vírus letal.

O movimento que se observou na Praça da Estação pode servir como medida para estender o conceito de invisibilidade também para outras realidades. Precisamos, porém, deixar clara a moldura que permitiu a visibilidade de situações que, no entanto, sempre estiveram presentes no cotidiano dos brasileiros. Quem nunca se deparou com os moradores de rua? Eles estão nos mesmos lugares que frequentamos ao utilizarmos os mais variados serviços essenciais. Que morador de Belo Horizonte nunca passou pela Praça da Estação e não os viu por lá? Ou melhor: por que, mesmo os vendo, não os percebeu? Por que essa praça, quase sempre lotada, teve que se esvaziar para que eles, que de lá nunca se ausentaram, pudessem, de fato, marcar presença? Eles, assim, puderam ser vistos na realidade que lhes é própria - a de quem mora nas praças e nas ruas -, exatamente porque, no momento em que todos tiveram que ficar em casa, como a casa deles era ali, ali ficaram. O fundo da questão, logo se vê, é a moradia (ou a falta dela), um dos indicativos mais claros e contundentes da desigualdade que a pandemia nos mostra com contornos dramáticos pouco vistos na história recente do país.

\subsection{Invisíveis na Educação}

A desigualdade estrutural, portanto, foi o que, de fato, se fez ver. Dessa forma, pode-se dizer que existem também muitos invisiveis no âmbito escolar, caso se faça apenas um deslocamento de olhar, da moradia para a educação, dois dos mais visíveis campos nos quais se encontra uma enorme população de desassistidos. Quem são, então, os invisíveis que a pandemia nos fez ver dentro das escolas? Para responder, convém mencionar como esta questão apareceu dentro de um grupo de professores da UEMG do qual faço parte e que pesquisa, reflete e propõe ações, tendo realidades ditas periféricas como foco. O grupo formou-se em 2019 e, com isso, a UEMG passou a participar de uma rede de universidades que implementou o projeto Encontro de Saberes, com apoio do Conselho Nacional de Desenvolvimento Científico e Tecnológico (CNPq)

A Universidade Federal de Minas Gerais (UFMG), desde 2014, faz parte da rede e é uma das pioneiras em tomar iniciativa de incluir não apenas os saberes tradicionais nos currículos acadêmicos, mas também fazer com que os mestres e mestras desses saberes possam tornar-se parte do seu corpo discente e docente. Em maio passado, instituiu o chamado Notório Saber, por meio do qual reconhece a capacidade dos mestres indígenas, quilombolas, da cultura popular e das comunidades afrobrasileiras de se tornarem professores em matérias regulares, valendo crédito, e não somente nos programas de extensão. O título é equivalente a um doutoramento, conferindo, portanto, todos os direitos e deveres de docentes de uma universidade federal ou estadual (cf. UNIVERSIDADE FEDERAL DE MINAS GERAIS, 2020). Essa iniciativa coroa a política de cotas nas escolas públicas superiores do Brasil, oficialmente implantada em 2012.

Antes, porém, muitas universidades já caminhavam na direção das chamadas ações afirmativas. A UEMG foi uma das primeiras universidades estaduais a trilhar este caminho, começou ainda em 2005, quando entraram, por meio de cotas, estudantes vindos das escolas públicas e que possuíam, comprovadamente, baixa renda. Hoje, se mais de $80 \%$ dos estudantes da UEMG são egressos de escolas públicas é porque esta universidade foi a primeira instituição de ensino superior de Minas Gerais, e uma das primeiras universidades estaduais do Brasil, a estar sensível à realidade de estudantes em situação de vulnerabilidade. Em 2019, o programa de cotas incluiu também alunos vindos de realidades quilombolas e ciganas.

Não resta dúvida de que a política de cotas mudou a paisagem das universidades públicas brasileiras, antes, quase exclusivamente, compostas por pessoas de cor branca e com renda acima da 
média. Hoje, mais da metade dos alunos são oriundos de famílias de pessoas de cor negra ou parda, como constata a pesquisa Desigualdades Sociais por Cor ou Raça no Brasil do IBGE (Instituto Brasileiro de Geografia e Estatística), com dados referentes aos anos de 2016 a 2018 (INSTITUTO BRASILEIRO DE GEOGRAFIA E ESTATÍSTICA, 2018). As políticas públicas de inclusão, implantadas ainda na década de 1990, começaram, de fato, a surtir efeito, segundo o IBGE, que também atribui a melhora como resultado da escolaridade acumulada ao longo dos anos.

Tão logo constata a melhora, o IBGE adverte: "No entanto, a desvantagem da população preta ou parda em relação à população branca continuou evidente" (INSTITUTO BRASILEIRO DE GEOGRAFIA E ESTATÍSTICA, 2018, p. 7). E mais: na própria população negra e parda fica cada vez mais evidente uma parcela ainda mais vulnerável. Aqui está um primeiro esboço para compor o que sejam os invisiveis no âmbito da educação, sendo exemplos: a situação de negros ou pardos que moram no interior das cidades mais afastadas dos grandes centros; ou a daqueles que, mesmo morando em cidades com oferta vasta de vagas nas escolas, acabam por desistir do estudo para trabalhar, o que pode se intensificar na situação pós-pandemia. Em 2018, dos jovens de 18 a 24 anos com Ensino Médio completo que não estavam frequentando a escola pelos motivos citados, $61,8 \%$ eram pretos ou pardos, segundo o IBGE (INSTITUTO BRASILEIRO DE GEOGRAFIA E ESTATÍSTICA, 2018, p. 7).

\subsection{Invisíveis na UEMG}

O que parecia invisivel mostrou-se, porém, na sua face bem conhecida, apesar de ignorada. Quem está atento ao cotidiano escolar percebe que a geração atual de alunos, disposta à conexão, apresenta uma vulnerabilidade que a atinge exatamente naquilo que a distingue de outras gerações, que não dispunham de alta tecnologia de comunicação - como a que passou a ser usada para tornar possíveis as aulas remotas. A participação nessas aulas, no entanto, não foi possível a todos, uma vez que não se atentou ao fato de uma grande parcela do alunado não dispor das condições mínimas para participar do ensino a distância. Esse diagnóstico já havia sido claramente sinalizado na avaliação dos questionários que a Reitoria da UEMG enviou para alunos e professores a respeito da proposta de conduzir o semestre de modo virtual. Entre os dias 8 e 9 de maio, cerca de 11.697 alunos $(56 \%$ do total matriculado) se prontificaram em responder, entre outras questões, sobre as dificuldades para seguirem as atividades remotas (UNIVERSIDADE DO ESTADO DE MINAS GERAIS, 2020a).

Nesse diagnóstico, duas realidades mostram-se na dimensão de invisibilidade. A primeira já é conhecida, embora nunca houvesse sido feito um levantamento como o realizado pela Reitoria: cerca de $15 \%$ dos discentes disseram não possuir uma linha de Internet capaz de colocá-los em conexão com os professores e colegas. Ficou, porém, uma pergunta quanto a estes que não sabíamos que existiam em proporção tão significativa: quem são esses alunos de curso superior de uma das maiores universidades públicas do Brasil que não possuem sequer um computador para assegurar um suporte para as suas atividades escolares? Por que essa parcela, nada desprezível, de alunos da UEMG pode ser considerada invisivel, na lógica governamental que passou a aplicar esse adjetivo àqueles que não se enquadravam nos cálculos previstos para terem direito ao auxílio emergencial?

Para responder às questões, é preciso atentar ao fato de que o IBGE atesta aumento considerável do uso da Internet por parte da população negra ou parda entre os anos de 2016 e 2017, segundo a pesquisa sobre as desigualdades sociais, mencionada anteriormente (INSTITUTO BRASILEIRO DE GEOGRAFIA E ESTATÍSTICA, 2018). Mais de 65\% das pessoas negras e pardas entrevistadas disseram ter inclusive dispositivos para o uso dos serviços online. As nuances da desigualdade, entretanto, não esmorecem nem mesmo quando se poderia comemorar uma mudança positiva. Isso porque a população negra ou parda continua muito aquém, se comparada com os índices da população de cor branca, esta com quase $75 \%$ dispondo de Internet, segundo o IBGE (INSTITUTO BRASILEIRO DE GEOGRAFIA E ESTATÍSTICA, 2018). Desigualdade que se destaca ainda mais quando considerado que cerca de metade dos negros ou pardos que não possuem acesso à Internet precisaria dela como ferramenta básica para não perder o semestre exclusivamente feito de modo remoto.

A segunda e maior invisibilidade, porém, está em outro dado atestado pela pesquisa da Reitoria da UEMG, quando se perguntou aos alunos (e também aos professores) quais seriam os principais obstáculos à implementação das aulas online. Mais da metade, de ambas as realidades, 
discente e docente, disse que as condições não envolviam tanto a tecnologia, mas o próprio corpo, sem condições emocionais para seguir as aulas (UNIVERSIDADE DO ESTADO DE MINAS GERAIS, 2020). Esse aspecto, tão presente em conversas das reuniões de colegiados nas escolas, é sempre deixado em um ângulo da problemática que é melhor não ver. No entanto, os problemas mentais advindos de um período muito prolongado de isolamento, nos mesmos lugares, com as mesmas pessoas, sem se frequentar ambientes de convivência, como a escola, estão em franco agravamento. Christian Dunker, psicanalista, constata isso em $A$ arte da quarentena para principiantes, livro no qual procura tratar um problema bastante sério, sem, porém, perder o humor (DUNKER, 2020).

Dunker, professor titular da Universidade de São Paulo, discorre também a respeito do sistema remoto de aulas, adotado por muitas universidades. Muitos protocolos preparados para as aulas começarem partem do pressuposto de que todos, se não possuem, podem providenciar as devidas condições técnicas, sem se considerar que não basta apenas ter um celular ou um computador munido de boa Internet. O que fica de fora, na avaliação do professor, são detalhes como, por exemplo, o lugar da recepção dessas aulas. O psicanalista associa a questão da moradia à da educação, agora pelo seu viés subjetivo, destacando o fato de que, além dos recursos tecnológicos, a situação nas famílias de muitos estudantes e professores complicou-se com a pandemia. Isso evidencia um aspecto que tem chamado a atenção de muitos educadores e psicólogos: sem pedir licença, a escola entrou nas casas das pessoas.

Este ângulo subjetivo não é coberto nem mesmo pela agudeza dos entrevistadores do IBGE, atentos a nuances das desigualdades racial e econômica. Ainda não foi criado um questionário por parte dos organismos oficiais para medir a qualidade da saúde mental da população, sobretudo depois da experiência traumática do confinamento e/ou da perda para a covid-19 de pessoas próximas. Assim como pouco se conhece sobre os que não se enquadravam sequer na categoria de "trabalhadores informais", que não haviam perdido renda pelo simples fato de não a possuírem; de tão invisíveis, não se sabe dizer quase nada sobre os desassistidos emocionais.

\subsection{Invisíveis no Design}

A UEMG possui uma Escola de Design e vários cursos dessa área nas suas mais diversas escolas, por isso, é pertinente apresentar a temática dos invisiveis como uma maneira de refletir sobre os efeitos da pandemia nas condições mais concretas da comunidade acadêmica desse segmento particular da universidade. Essa reflexão pode nos ajudar a recolocar uma antiga questão, que nunca saiu de pauta: a invisibilidade do campo do Design em nosso sistema econômico. Tal sistema tenta confinar esse campo apenas a estratégias comerciais, desconsiderando sua importância no enfrentamento de desafios socioculturais. A leitura enviesada de que a pandemia nos obrigou a lidar com um novo normal, ${ }^{2}$ embora amplamente disseminada no contexto atual, não demonstra a miopia existente diante de uma situação cuja crise é evidente há tempos.

"Crise",aliás, foi o termo usado por Gui Bonsiepe em artigo emblemático, no qual discorre a respeito do que podemos também considerar como invisibilidade, por ele detectada muito antes de a pandemia chegar. "Design e Crise", palestra proferida em 2011 na Universidade Autônoma Metropolitano, na cidade do México, primeiramente fotografa a posição do Design no campo das disciplinas universitárias de modo geral, apontando o não reconhecimento da sua validade acadêmica, por não ter merecido a devida atenção do pensamento filosófico. Na verdade, o sistema dominante universitário teve que lidar com um novo campo, o qual não sabia onde colocar, já que não se enquadrava devidamente nem na área das ciências, nem na das tecnologias, tampouco na das artes. Assim, passou a pedir "novos conhecimentos científicos" a uma área cujo olhar não mirava propriamente as academias, mas as práticas da vida cotidiana. "O Design enfoca o caráter operacional dos artefatos materiais e semióticos, interpretando a sua função e a funcionalidade não em termos de eficiência física, mas em termos de comportamento incorporado em uma dinâmica cultural e social" (BONSIEPE, 2012, p. 19).

A discussão é longa. Cabe mencionar, porém, que ela foca não apenas a relação do Design com a sociedade, como também deste consigo mesmo. Bonsiepe admite, no artigo em questão, que é

\footnotetext{
${ }^{2}$ De novo e normal não há nada, mesmo assim se solicita aos designers desenhar esse "novo normal".
} 
inútil pensar uma área tão dinâmica e tão estritamente ligada às mudanças socioculturais como fora de "crises".

Ao resgatar a etimologia da palavra crise, de origem grega, no sentido de uma mudança inevitável e decisiva, Bonsiepe (2012) possibilita fazermos uma inflexão no vasto tema que permeia seu livro, para voltarmos nossa atenção a alguns dos ecos de como a crise está afetando os alunos e professores de Design da UEMG - com evidentes reflexos nos currículos e didáticas colocadas à prova pela opção do ensino remoto.

Começamos pelo fato de que, assim como nos demais segmentos escolares da UEMG, a situação de vulnerabilidade atinge diretamente a comunidade acadêmica dos cursos e da Escola de Design, contrariando o imaginário da educação em Minas Gerais, segundo o qual, neste segmento, reside uma espécie de "elite" dos discentes e docentes dessa universidade estadual. Isso comprova a existência de um grande mal-estar, detectado sobretudo nos cursos de Design das escolas fora da capital mineira - alguns deles ainda em análise, devido à sua recente implantação.

É o caso do curso de Design de Moda da UEMG, na cidade de Passos. Logo depois do anúncio de que as aulas retornariam, no formato remoto, um grupo de estudantes tentou mudar os rumos da decisão. O caso mais emblemático chegou por meio do Centro Acadêmico Zuzu Angel, que organizou uma petição na plataforma AVAZZ.org Petições da Comunidade, assinada por 230 alunos e encerrada em 17 de julho de 2020. A grande maioria votou contra o início das aulas, como previsto pela Reitoria. Alguns dados da petição são motivo para se investigar, de maneira mais precisa, o que realmente significa a resistência à proposta de retomar o semestre mesmo sem a possibilidade do contato direto aluno/professor: $39,6 \%$ dos alunos não possuem local adequado para estudar em casa; $75 \%$ acreditam que seriam excluídos caso as aulas fossem retomadas remotamente. O que também chama a atenção, segundo a petição, é que, no geral, $70 \%$ do que responderam consideraram a situação de vulnerabilidade emocional como um dos efeitos da pandemia (AVAAZ.ORG, 2020). Mais uma vez, os invisiveis emocionais se fazem ver, embora suas demandas não tenham sido devidamente consideradas.

Na Escola de Design, em Belo Horizonte, começa a se infiltrar uma problemática que ainda luta para se mostrar como legítima. Talvez tenhamos que esperar algum tempo, para efetivamente ver a queixa de muitos alunos a respeito da carga horária despendida diante do computador ou do celular para dar conta de acompanhar as aulas, mesmo quando se trata de atividades em que não estão em contato online com o professor e colegas. Duas demarcações, porém, já podem ser incluídas nas análises, ainda que em estado embrionário. Uma mais geral, que se pode detectar pelo condensamento de atividades dentro de um semestre com cerca de 30 dias letivos a menos. Outra mais específica das disciplinas ministradas nos cursos de Design, que exigem práticas em oficinas e laboratórios, e que foram, de certo modo, obrigadas a migrar para uma tela de computador ou celular. Isso tem ocasionado o que já era previsto: um certo cansaço - que já é tema frequente na literatura nas áreas de tecnologia e pedagogia -, porque as aulas síncronas exigem um grau de concentração maior, segundo os especialistas. Por parte dos alunos de Design, as aulas práticas precisam encontrar meios menos cansativos de colocar o aluno em contato com as ferramentas das disciplinas projetuais.

\section{Saberes periféricos: que saber, que periferia?}

Considerando agora a realidade dos invisiveis no âmbito da educação, os membros do Encontro de Saberes da UEMG começamos a refazer a nossa proposta de um primeiro seminário, planejado, inicialmente, para que pudéssemos mostrar as nossas pesquisas com mestres e mestras indígenas, quilombolas, da cultura popular, das comunidades afrodescendentes e outros. Desde os primeiros anos da minha graduação, na Universidade Federal do Amazonas, na década de 1980, vejo-me comprometido com os saberes indígenas. De 2014 a 2017, estive muito envolvido com a formação de professores e artistas de Belo Horizonte como maneira de fazer acontecer os propósitos da Lei $\mathrm{n}^{\mathrm{o}}$ 11.645, de 2008, que tornou obrigatório o ensino das culturas indígenas e afro-brasileiras nas escolas públicas. A partir do momento em que assumi uma vaga de professor na UEMG, em outubro de 2017, esse projeto teve que ser paralisado, mas sua retomada foi propiciada pela formação do grupo Encontro de Saberes.

No entanto, para o seminário, tive que abrir mão do tema propriamente indígena - sobre o qual já dispunha de considerável volume de textos, imagens, artefatos colhidos durante o período de doutorado e pós-doutorado em Literatura Comparada na UFMG -, para que desse crédito a alguns 
questionamentos sobre as nossas pesquisas a respeito dos chamados saberes periféricos. Tendo que justificar o deslocamento de uma abordagem ancorada em saberes tradicionais para um tipo de saber que, por não ter "tradição", muito menos poder se constituir como "saber" no modo que geralmente entendemos esses termos na academia, fui levado a fazer algumas reflexões que gostaria de compartilhar.

Chamo essas reflexões de "o não saber dos invisíveis". Trata-se de uma maneira de explorar o termo invisivel que surgiu na mídia, mas que se tornou um ponto de reflexão e inflexão a respeito da condição de vida das populações cuja situação de alta vulnerabilidade se mostrou por causa da covid19. Isso pode nos ajudar a fazer um questionamento a respeito do conceito de saberes periféricos. Duas são as questões que vamos levantar. Primeiramente, perguntar de que tipo de periferia se está falando quando se trata de focar em uma população que se constitui exatamente por não apresentar qualquer forma de organização do tipo que marca as periferias tradicionais, cujas pautas de reivindicação por direitos básicos de alguma forma possuem ressonâncias nos organismos governamentais, em parlamentos e tribunais. Depois, perguntar se seria possível falar propriamente em "saberes", assim como também se fala dos grupos periféricos, como índios e quilombolas, que evidentemente possuem um corpo substancioso de saberes e fazeres que constitui uma das suas forças mais poderosas na reivindicação de direito por terra, moradia, expressividade.

Como os invisiveis sempre existiram de fato, a sua visibilidade pode ser considerada como uma das ironias que o destino do novo corona vírus assumiu no Brasil. A situação de alto risco no qual se encontrou fez com que essa população, de alguma maneira, se organizasse, mas essa organização não se deu de maneira tradicional. Aqui, podemos voltar à Praça da Estação. A população de rua, como uma maneira de se prevenir do vírus, saiu dos seus antigos esconderijos espalhados pelo centro da cidade e em bairros periféricos e escolheu, preferencialmente, dois lugares do centro - a citada Praça da Estação e a Praça da Rodoviária - como pontos de concentração. Isso, de certa forma, chamou a atenção dos agentes defensores de direitos humanos, que passaram a organizar uma condição mínima para ajudar essa população não somente na questão sanitária, mas também na econômica. A filial da Pastoral da Rua, da Conferência Nacional dos Bispos do Brasil (CNBB), em Belo Horizonte, montou uma espécie de abrigo na Serraria Souza Pinto, na Praça da Estação, de modo que os moradores de rua pudessem se alimentar, tomar banhos, fazer o teste rápido para covid e encaminhar o pedido do auxílio emergencial (cf. GUIMARÃES, 2020).

O Canto da Rua, como a iniciativa foi chamada, tornou-se assim uma espécie de local emblemático onde foi possível ver a maneira como os invisiveis se mostraram a partir dos efeitos provocados pela pandemia. Tudo foi montado às pressas, com auxílio de várias entidades, como os setores do comércio e bancário, a defensoria pública e um conjunto grande de voluntários, na perspectiva de que tudo era, de fato, provisório, com data de desmontagem marcada para o início de agosto. Ainda não é possível medir o alcance do benefício que a iniciativa acarretou a uma população que, por ironia do vírus, passou a ter assegurados alguns direitos que sempre lhes foram negados. Um efeito, porém, é certo: fez-nos ver o que se chamou de invisivel, mas que era apenas uma maneira de não querer notar o que se está vendo claramente.

Se tomarmos o Canto da Rua como metáfora do que os invisiveis nos fizeram ver, podemos dizer que, neste caso, o de quem não possui nada - nem terra, nem casa, nem família, nem documento -, é claro que também não possui qualquer coisa a nos ensinar, porque está despojado até mesmo dos mínimos saberes. No entanto, ironicamente, essa dialética perversa do vírus, que tirou todas as pessoas da rua, fez com que aqueles que dela nunca saíram pudessem, enfim, ocupar os lugares que são seus e sempre lhes foram negados, dos quais nunca saíram, mas nos quais nunca foram vistos. Pela mesma contradição irônica do vírus, a população de invisiveis que mora nas ruas de Belo Horizonte fez ver exatamente isso: que eles moram nas ruas, que as praças são suas casas. Por essa condição ser o modo de existência deles, quando a cidade ficou isolada, eles, enfim, puderam ser vistos e mostrar (inclusive a si mesmos) a própria invisibilidade. Nada mais, nada menos.

O que cabe perguntar agora é se, nisso que eles nos fizeram ver, existe algum tipo de "saber". Sim, diríamos, os invisiveis possuem um tipo muito particular de saber, aquele dos seres invisiveis, que mostram exatamente o que não se quer ver, a própria invisibilidade. Esta, de fato, existe, e ela se traduz na existência de uma população cuja periferia não está propriamente na periferia, mas no centro da cidade; e, se a periferia, no entanto, continua existindo como tal, são muitas. Os invisíveis são a periferia do centro e atestam que, na periferia, eles ocupam o lugar de periferia. São, por isso, a 
periferia da periferia, aquela que não tem relação com o centro porque é o próprio coração do centro, as barracas montadas na Praça da Estação.

A reflexão, portanto, pretende fazer um questionamento sobre o que é ser periferia e como uma periferia que se define por ser periférica dentro da própria periferia possui um "não saber" profundamente poderoso e atual para nos fazer ver aquilo que só se mostra porque é, exatamente, invisivel. O não saber dessa periferia da periferia que nos faz ver o invisivel pode ser o grande motor de uma política de visibilidade da qual carecemos exatamente porque tendemos a não mais colocar os termos das nossas pesquisas sobre os saberes periféricos em questão. A situação que fez os invisíveis se tornarem evidentes, portanto, deve estar presente no debate, que se completa com a questão do saber que nossas pesquisas procuram evidenciar quando tematizam exatamente as periferias. Será que um tipo de saber como esse não saber dos invisíveis tem, realmente, espaço em nossas universidades?

\section{Desigualdades}

\subsection{Desigualdade Estrutural}

A pergunta com a qual concluímos a reflexão a respeito da organização do seminário Saberes Periféricos do grupo de pesquisa Encontro de Saberes da UEMG, na verdade, retoma, ou, se preferirmos, torna novamente visível uma problemática antiga, que esteve muito presente nos circuitos universitários do Brasil na década de 1940 e que, no entanto, continua aberta, como uma veia dilatada, sem que até hoje tenhamos uma resposta convincente. Trata-se do que o sociólogo Florestan Fernandes, já no longevo ano de 1975, quando do lançamento do seu livro A Revolução Burguesa no Brasil, definia exatamente como "desigualmente estrutural" (FERNANDES, 1975). Por que a discussão, nos moldes definidos por Florestan, ainda continua tão fresca? Este foi o foco de um interessante artigo de Antônio Brasil Júnior, professor de Sociologia da Universidade Federal do Rio de Janeiro, intitulado "A resistência da desigualdade" (BRASIL JÚNIOR, 2020, p. B14). O professor resgata a problemática que Florestan chamou de "autocracia burguesa", principal conceito do livro citado anteriormente. "Entender como e por que a formação do capitalismo entre nós não gerou uma sociedade minimamente civilizada e democrática foi uma verdadeira obsessão de Florestan", escreve Brasil Júnior (2020, p. B14), lembrando 2020 como o centenário de nascimento do sociólogo referência para os estudos da desigualdade racial desde o momento em que foi publicado o seu livro $A$ Integração do Negro na Sociedade de Classe, em 1965 (FERNANDES, 1965).

Integração que, na verdade, nunca ocorreu de maneira significativa apesar dos avanços evidentemente notados. Nesse sentido, os invisiveis são realmente uma velha realidade conhecida do Brasil, desde o momento em que começaram a ser feitas estatísticas para medir o nível de vida da população, ainda no final do século XX. Para a Pastoral de Rua da CNBB, os moradores de rua não apenas sempre estiveram bem à vista, como também possuem uma cor dominante, a negra. Isso foi, mais uma vez, constatado pelo trabalho no Canto da Rua, como lembra Cristina Bove, uma das coordenadoras do serviço. ${ }^{3}$ Ela não tem dúvida de que a maioria daqueles que frequentaram o local eram negros ou pardos. Essa percepção tende, de alguma forma, a respaldar as estatísticas, segundo o IBGE, o qual constatou que, apesar de serem pouco mais da metade da força de trabalho brasileira $(54,9 \%)$, as pessoas de cor negra ou parda formavam cerca de dois terços dos desocupados $(64,2 \%)$ e dos subutilizados $(66,1 \%)$ na força de trabalho em 2018 (INSTITUTO BRASILEIRO DE GEOGRAFIA E ESTATÍSTICA, 2018, p. 2).

Podemos fazer um paralelo entre o momento em que Florestan Fernandes estava pensando nas possibilidades que ajudariam a diminuir o número de desempregados no Brasil e as promessas atuais que vão nessa mesma direção. A cidade de São Paulo, em um momento crucial do seu processo de urbanização e industrialização, entre as décadas de 1950 e 1990, foi o objeto privilegiado da observação do sociólogo. Havia no ar, portanto, a ideia de que essa realidade iria criar mais postos de trabalho, o que realmente ocorreu. Mas jamais se resolveu, de fato, o problema do desemprego; ao contrário, este até se agravou, se visto na perspectiva um tanto realista de Florestan Fernandes. Ele nunca acreditou que o aumento da possibilidade de emprego atingiria, efetivamente, uma população

\footnotetext{
${ }^{3}$ Ela nos concedeu uma entrevista no dia 25 de junho de 2020, depois de termos feito uma visita ao local, na Praça da Estação.
} 
que, por não dispor de educação qualificada, estaria sempre às margens das exigências tecnológicas do mercado em ascensão.

\subsection{Desigualdade Digital}

A problemática que gira em torno da tecnologia como meio de aprimorar o campo de trabalho, tornando-o supostamente mais democrático, já estava na pauta da sociologia praticada por Florestan Fernandes. Hoje se pode, dessa forma, observar o (re)aparecimento dos invisiveis justamente por esse viés. No âmbito escolar, isso pode ser visto de maneira paradigmática, uma vez que é exatamente buscando auxílio em uma tecnologia de ponta que surge a solução mais possível para manter as escolas em funcionamento em tempos de pandemia. Será que isso colabora no posicionamento de quem faz menção às potencialidades da Internet para democratizar o acesso à educação formal?

Considerando alguns dados da Unesco, organismo das Organizações das Nações Unidas (ONU) para a educação, é provável que as escolas que aceitaram a solução da aula remota estejam, na verdade, contribuindo para aumentar a desigualdade entre alunos que possuem recursos disponíveis para acompanhar esse modo de ensino e os que não só não têm recursos, como, na verdade, nunca os possuíram e não veem perspectiva de posse em curto prazo. Essa é opinião da diretora da Unesco, Stefania Gianni, que deu recentemente entrevista ao jornal Folha de S.Paulo, dizendo que acompanha com preocupação a situação do Brasil, já que a pandemia entre nós continua, em pleno início do segundo semestre de 2020, em progressivo crescimento (GIANNI, 2020, p. A7).

$\mathrm{Na}$ entrevista, a diretora da Unesco é categórica ao afirmar que a pandemia já teve o seu efeito muito claro na educação: aumentou, de fato, a desigualdade, que agora pode ser medida pelas condições de alunos em terem aula remota. Isso é constatado também na rica e bem ordenada Europa, onde cerca de $14 \%$ dos alunos não possuem Internet em casa, o que possibilitaria entrar no modelo optado pela maioria das escolas ao retornarem às aulas em agosto de 2020. Quando o olhar se volta para a África, a situação realmente causa espanto: os números chegam a mais de $80 \%$ dos alunos. Mas não estamos em um mundo conectado? De que mundo e de que conexão está se falando? É preciso responder tais perguntas, para que o espanto seja, de alguma forma, dissipado, ou melhor, colocado em seu devido lugar: o daquele que sempre soube que, em um mundo conectado, a metade dele ainda espera poder se conectar.

\subsection{Desigualdade Proposital}

Os invisiveis do nosso tempo não estão apenas nas ruas e praças, mas também dentro de escolas, e colocam a pergunta sobre se realmente estão esperando entrar no mundo digital. Quanto mais as escolas estão afastadas dos grandes centros, e, portanto, com mais possibilidade de estarem invisiveis, mais é visível a pergunta feita por elas. De longe, porém, são observadas como aquelas às quais devemos levar a conexão, já que não podem esperar por muito tempo. Aqui surge mais uma questão levantada por Stefania Gianni, quando traça as alternativas para que se possa lidar com as aulas neste momento em que a maior lição vem de um vírus com alto poder de contágio. Quando pensa nos lugares com muita dificuldade de conexão, como entre os moradores dos Andes latino-americanos, por exemplo, ela fala de uma conversa que teve com o atual ministro da Educação do Peru, Carlos Martin, da qual saiu convencida de que, mais do que "levar" a educação para os povos indígenas que moram entre as montanhas, é preciso aprender com o que eles já fazem e potencializar esse aprendizado que está completamente envolvido pela maneira como alguns povos andinos tratam a própria língua como estratégia imprescindível para melhorar o nível de educação de suas crianças e adultos. "Para muitos indígenas da América Latina, uma grande parte da inclusão educacional passa por isso", diz a diretora da UNESCO (GIANNI, 2020, p. A7).

Sabemos, porém, que a realidade dos indígenas brasileiros no cenário hostil do avanço do corona vírus nas aldeias tem se tornado cada vez mais dramática, pois não existe qualquer plano do Governo Federal para conter este avanço, tampouco para tentar resolver o problema da educação que essa situação tem gerado. Isso levou a Comissão Externa da Câmara dos Deputados do Brasil a fazer um relatório para mostrar o quanto nada foi feito por parte do Executivo para promover a educação durante a pandemia. O relatório diz que, até julho de 2020, nenhuma medida havia sido tomada no sentido de equacionar os graves problemas ocasionados pelo contágio do corona vírus nas comunidades 
rurais, entre os povos indígenas e quilombolas. O Ministério da Educação rebateu dizendo que ainda não tinha como responder às questões colocadas pelos parlamentares (GOMES, 2020).

É preciso lembrar, no entanto, que, no âmbito da educação, muitas comunidades indígenas se preparam para conquistar alguma autonomia em relação ao ensino praticado nas escolas formais e que, por muito tempo, se tentou impor aos povos indígenas. A conquista veio com a Constituição de 1988, que implantou a chamada "educação diferencial indígena", a partir da qual nasceram escolas no interior dos grupos, com professores indígenas capacitados para ensinar a língua nativa como maior veículo de aprendizado. Foi, então, que surgiu a oportunidade dos índios escreverem seus próprios livros. Hoje existe uma coleção significativa do que os antropólogos chamam de "livros da floresta". Neles, pode-se aprender, inclusive, novas formas de ensinar. Mas tais livros continuam, no entanto, invisiveis para a grande maioria dos educadores e do público em geral.

Não é difícil encontrar a Internet entre os grupos indígenas, e, graças à chegada do mundo virtual às aldeias, a produção audiovisual indígena deu um salto considerável. Vicent Carrelli, o fundador da Organização Não Governamental Vídeos nas Aldeias, recentemente dispôs na rede o catálogo de obras que surgiram nos últimos 20 anos (cf. D’ANGELO, 2020). Os índios sabem que a Internet é imprescindível no modo de comunicação no qual eles também se encontram envolvidos assim como todo o mundo - e, talvez, possam nos ensinar a fazer a diferença entre comunicação e aprendizagem. Para eles, a Internet é de grande serventia se estiver a serviço da cultura local. Nesse sentido, preferem realmente ser diferentes da maioria, colocam-se, portanto, propositalmente, na condição de invisiveis, mas como uma estratégia para reinventar a rede ao seu modo, como comprova boa parte da produção cultural que hoje chega das aldeias.

\section{Conclusão: "Ampliar o conhecimento sem aumentar a desigualdade"}

$\mathrm{O}$ diagnóstico da reitoria da UEMG, ainda que feito às pressas, indicou a precariedade na qual se encontraram professores e alunos tendo que aderir a uma nova modalidade de ensino sem dispor dos recursos adequados para lhes dar alguma segurança maior. Estamos curiosos para saber quem realmente são os $15 \%$ de estudantes que, no diagnóstico feito pela Reitoria da UEMG, assim como boa parte do curso de Design de Moda de Passos, disseram não possuir Internet adequada para as aulas remotas. Essa parcela do alunado não teria a mesma cor dos que Florestan lutou para tornar visíveis, apesar de suas demandas serem claramente expostas e colocadas para as autoridades que poderiam fazer alguma coisa para atendêlas?

Tais questões se fazem urgentes exatamente porque a escola, pós-pandemia, assinala uma mudança radical, como aquela observada na São Paulo de Florestan Fernandes. Na linguagem desse sociólogo, os subalternos, de modo particular a população de cor negra e parda, sempre tiveram dificuldade para uma ação coletiva. O capítulo "O Modelo Autocrático-Burguês de Transformação Capitalista", de A Revolução Burguesa no Brasil (1975), livro que acaba de ser relançado pela Editora Contracorrente, mostra as atualidades da abordagem de 45 anos atrás (FERNANDES, 2020, p. 337-347). Devido ao passado escravocrata, a população negra, segundo o sociólogo, ficou em piores condições no ponto de partida da transição do mundo rural à sociedade urbana industrial quando a maior cidade do país passava por um processo radical de mudança econômica.

Para conseguir dar início às aulas remotas, a Reitoria da UEMG preparou guias para estudantes e professores. Neles constam várias informações a respeito de como é possível equalizar os problemas que podem advir do uso da plataforma Teams, da Microsoft, escolhida pela universidade para aulas remotas (UNIVERSIDADE DO ESTADO DE MINAS GERAIS, 2020b). No caso do guia para discentes, além de conter orientações para os alunos sobre matrículas e outros processos burocráticos, tenta passar também uma mensagem de otimismo quanto ao que considera os desafios para a escola do futuro. A situação, porém, não é muito favorável para o ingresso da UEMG no mundo digital. Vale lembrar que $75,7 \%$ dos alunos e $63, \%$ dos professores, ao serem perguntados sobre a mudança das atividades presenciais para aquelas online, foram categóricos: acreditam firmemente que haverá uma perda considerável. Não se sabe ainda, com clareza, o que seria essa perda. Ela, porém, já está contida em advertências que chegam desde o tempo em que Florestan Fernandes pesquisava com afinco as raízes da desigualdade crônica brasileira. Elas são remotas. Remoto é também um nome para o rosto contemporâneo da desigualdade. Fica, porém, o consolo que o guia para o ensino emergencial da UEMG não deixa de nos oferecer: "Ampliar o conhecimento sem aumentar a desigualdade". A utopia está lançada. 
The Invisibles of UEMG and Others Education Invisibilities during Pandemic Times

Abstract: The paper approximates the reality of Minas Gerais State University (UEMG) students and teachers, particularly design courses, in its vulnerable situation to that one which has arisen after the release of the Federal Government emergency aid and which has been called invisibles. Actually, what has arisen concerns to one of the chronic social inequality faces in Brazil, which has been already diagnosed by the sociologist Florestan Fernandes studies between the 40s and 70s of the last century. Bourgeois autocracy was one of the concepts that he came up with to observe how the economic system produces a range of ways to keep the disparity between a minority that owns more than a half of per capita income of the country and a huge portion of the population totally unassisted and that tends to increase in a post-pandemic situation.

Keywords: invisibles; social inequality; bourgeois autocracy

\section{Referências bibliográficas}

AVAAZ.ORG. Contra as Aulas Remotas do Curso de Design de Moda - UEMG Unidade

Passos. Petição AVAZZ.org Petições da Comunidade, 17 jun. 2020. Disponível em:

$<$ https://secure.avaaz.org/community_petitions/po/reitoria_da_universidade_contra_as_aulas_remot as_no_curso_de_design_de_moda_uemg_unidade_passos_/ >. Acesso: 14 ago. 2020.

BONSIEPE, Gui. Design e Crise. In: Design Como Prática de Projeto. São Paulo: Blucher, 2012. p. 19-26.

BRASIL JÚNIOR, Antônio. A Resistência da Desigualdade. Folha de S.Paulo, 26 jul. 2020.

Ilustríssima, p. B14.

D'ANGELO, Helô. Plataforma Online Vídeo nas Aldeias Disponibiliza Documentário de Cineastas Indígenas. Site Revista Cult, 2020. Disponível em:

$<$ https://revistacult.uol.com.br/home/plataforma-online-disponibiliza-documentarios-de-cineastasindigenas/> Acesso em: 14 ago. 2020.

DUNKER, Christian. A Arte da Quarentena para Principiantes. São Paulo: Boitempo, 2020.

FERNANDES, Florestan. A Integração do Negro nas Sociedades de Classe. São Paulo: Dominus, 1965.

FERNANDES, Florestan. A Revolução Burguesa no Brasil. São Paulo: Zahar Editores, 1975.

GIANNI, Stefania. Assim como a Crise da Ebola, Covid-19 pode Aumentar Evasão Escolar Feminina. Folha de S.Paulo, 2 ago. 2020. Entrevista a Daniela Arcanjo, p. A7.

GOMES, Pedro Henrique. Governo não Adotou Medidas para Promover Educação Inclusiva na Pandemia, diz Relatório. G1, 2020. Disponível em:

<https://g1.globo.com/educacao/noticia/2020/08/11/governo-nao-adotou-medidas-para-promovereducacao-inclusiva-na-pandemia-diz-relatorio.ghtml>. Acesso: 14 ago. 2020.

GUIMARÃES, Elian. Colorido das Barracas Expõe o Aumento da Pobreza em Belo Horizonte. Estado de Minas, 5 ago. 2020. Disponível em: <https://www.msn.com/pt-br/noticias/brasil/colorido-dasbarracas-exp\%c3\%b5e-o-aumento-da-pobreza-em-belo-horizonte/arBB17ACFp?li=AAggNbi\&ocid=UP97DHP>. Acesso em: 14 ago. 2020. 
INSTITUTO BRASILEIRO DE GEOGRAFIA E ESTATÍSTICA. Desigualdades Sociais Por Cor ou Raça no Brasil. Estudos e Pesquisas - Informação Demográfica e Socioeconômica, n. 41, Biblioteca do IBGE, 2018. Disponível em:

<https://biblioteca.ibge.gov.br/visualizacao/livros/liv101681_informativo.pdf>. Acesso em: 14 ago. 2020.

UNIVERSIDADE DO ESTADO DE MINAS GERAIS. Levantamento Busca Entender Realidade de Estudantes e Docentes da UEMG. Site UEMG.BR, Notícias da UEMG, 12 maio 2020a. Disponível em: <http://www.uemg.br/noticias-1/4220-resultado-pesquisa\#Estudantes>. Acesso em: 14 ago. 2020.

UNIVERSIDADE DO ESTADO DE MINAS GERAIS. Guia do Docente Para o Ensino Remoto Emergencial e Ensino Remoto Emergencial Guia para Discente. Site UEMG.BR, 2020b. Disponível em: <http://uemg.br/docentes2020 > e <http://uemg.br/discentes2020>. Acesso em: 14 ago. 2020.

UNIVERSIDADE FEDERAL DE MINAS GERAIS. Conselho Universitário Regulamenta Reconhecimento de Notório Saber pela UFMG. Boletim da UFMG, n. 2.091, ano 46, Edição Especial, 2 jul. 2020. Disponível em:

<https://ufmg.br/storage/6/0/4/f/604f75cdf98cab44c3b66cd86baded39_15936922436563_20401845 99.pdf>. Acesso em: 14 ago. 2020. 